\title{
Diverse Roles of TgMIC1/4/6 in the Toxoplasma Infection
}

\author{
Jinjin Zhu, Yang Wang, Yuanyuan Cao, Jilong Shen and Li Yu* \\ The Key Laboratory of Microbiology and Parasitology of Anhui Province, The Key Laboratory of Zoonoses of High \\ Institutions in Anhui, Department of Microbiology and Parasitology, School of Basic Medical Sciences, Anhui Medical \\ University, Hefei, China
}

OPEN ACCESS

Edited by: José Roberto Mineo, Federal University of Uberlândia, Brazil

Reviewed by:

Silas Santana,

Universidade Federal dos Vales do Jequitinhonha e Mucuri (UFVJM),

Brazil

Ademilson Panunto-Castelo,

University of São Paulo, Brazil

*Correspondence:

Li Yu

lilyyu33@126.com

Specialty section:

This article was submitted to Microbial Immunology,

a section of the journal

Frontiers in Microbiology

Received: 10 February 2021 Accepted: 25 May 2021

Published: 17 June 2021

Citation:

Zhu J, Wang Y, Cao Y, Shen J and Yu L (2021) Diverse Roles of

TgMIC1/4/6 in the Toxoplasma

Infection.

Front. Microbiol. 12:666506 doi: 10.3389/fmicb.2021.666506
Toxoplasma gondii microneme is a specialized secretory organelle that discharges its contents at the apical tip of this apicomplexan parasite in a sequential and regulated manner. Increasing number of studies on microneme proteins (MICs) have shown them as a predominant and important role in host cell attachment, invasion, motility and pathogenesis. In this review, we summarize the research advances in one of the most important MICs complexes, TgMIC1/4/6, which will contribute to improve the understanding of the molecular mechanism of $T$. gondii infection and provide a theoretical basis for the effective control against $T$. gondii.

Keywords: Toxoplasma gondii, MIC1, MIC4, MIC6, invasion

\section{INTRODUCTION}

Toxoplasma gondii is an obligate intracellular protozoan parasite of the phylum Apicomplexa with a unique apical complex composed of specialized cytoskeletal and secretory organelles, including rhoptries and micronemes. Microneme proteins (MICs) are known to be essential for the parasite invasion and adhesion to host cell (Carruthers and Sibley, 1997; Carruthers and Boothroyd, 2007; Santos and Soldati-Favre, 2011; Sibley, 2011). The expression of MICs is mostly in the form of functional complexes composed of adhesive and transmembrane domain-containing proteins, including TgMIC1/4/6, TgMIC3/8, TgMIC2/M2AP, and a complex of the apical membrane antigen 1 (TgAMA1) with rhoptry neck complex formed by $T$. gondii rhoptry neck protein (TgRON) 2, TgRON4, TgRON5, and TgRON8 (Cerede et al., 2005; Huynh and Carruthers, 2006; Sheiner et al., 2010; Besteiro et al., 2011; Lamarque et al., 2011; Checkley et al., 2015). Most MICs contain a series of structural domains such as thrombospondin type I-like repeat (TSR), apple-like, epidermal growth factor-like (EGF) and chitin binding-like (CBL) domains, etc. (Tomley and Soldati, 2001; Anantharaman et al., 2007) which share homology with higher eukaryotic proteins ligand domains or adhesive motifs. This might account for parasite's ability to infect a wide range of host cell types (Sheiner et al., 2010; Boucher and Bosch, 2015). TgMIC1/4/6, the first found and the most extensively investigated microneme complex in T. gondii, is composed of soluble adhesion proteins TgMIC1, TgMIC4, and transmembrane escorter protein TgMIC6 (Brecht et al., 2001; Cerede et al., 2005; Saouros et al., 2005; Marchant et al., 2012; Paing and Tolia, 2014). More and more evidence show that TgMIC1/4/6 complex not only participates in the invasion of $T$. gondii, but also in the pathogenesis and immune escape of the parasite. This review aims to provide a more comprehensive understanding of the multiple roles of the TgMIC1/4/6 in T. gondii infection. 


\section{STRUCTURE CHARACTERISTICS AND SECRETORY REGULATION OF TgMIC1/4/6}

TgMIC1 is one of the earliest identified MICs in T. gondii, which was obtained from tachyzoites by Fourmaux et al. (1996) through the monoclonal antibody screening in 1996. The micl gene is 2,912 bp in length and contains three introns, and its open reading frame is $1,368 \mathrm{bp}$, encodes 456 amino acid residues with a predicted molecular mass $(\mathrm{Mr})$ of $49 \mathrm{kDa}$. The $\mathrm{N}$-terminal region of TgMIC1 possesses two micronemal adhesive repeat (MAR) domains formed by alternating stacked layers of tryptophan and arginine residues (Blumenschein et al., 2007; Garnett et al., 2009), which are certain homologous to thrombospondin 1 (TSP1) -like domain of thrombospondin-related anonymous proteins (TRAP) family in the Plasmodium falciparum. Importantly, the MAR domains have sialic acid lectin properties (Blumenschein et al., 2007; Garnett et al., 2009; Friedrich et al., 2010; Marchant et al., 2012), which can not only recruit TgMIC4 (Figure 1), but also interact with various sialic oligosaccharides on the surface of host cells. Analysis of the C-terminal structure of TgMIC1 revealed a non-functional galectin-like domain lacking sugarbinding residues, replaced by hydrophobic amino acids, which can interact with TgMIC6 and assist in folding and stabilizing

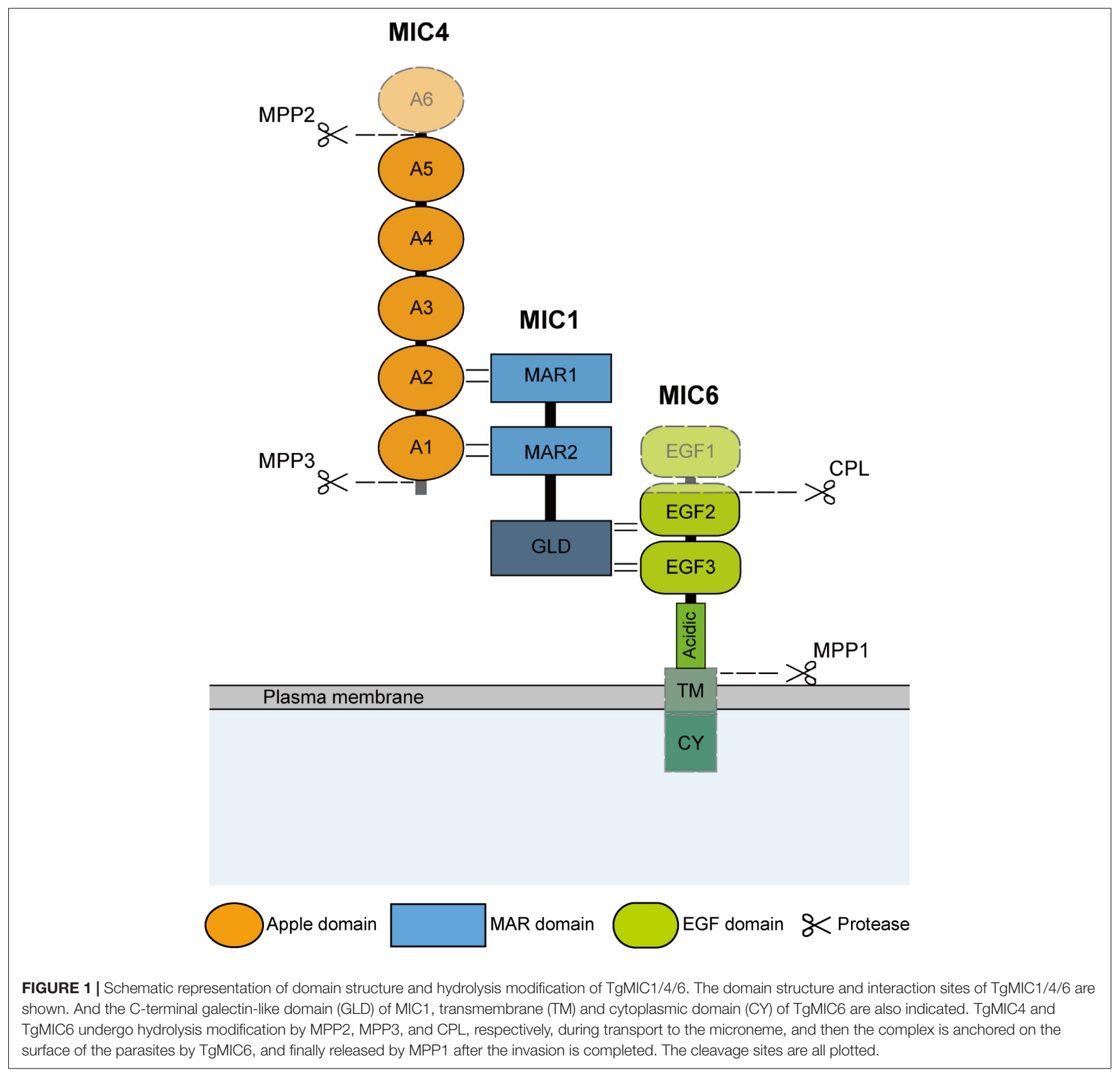


the third EGF domain and its C-terminus extended acidic region (Saouros et al., 2005; Gay et al., 2014). Importantly, TgMIC1 is critical to ensure the successful exit of TgMIC1/4/6 from the early compartment of the secretory pathway, and helps the complex target the micronemes correctly. The absence of TgMIC1 leads to the accumulation of TgMIC4 and TgMIC6 in the perinuclear region, endoplasmic reticulum (ER) and Golgi (Di Cristina et al., 2000). Therefore, as a bridge for complex assembly, the knockout of the micl gene alone is equivalent to the destruction of the complex overall function. Compared with the wild type, the invasion efficiency of TgMIC1 knockout strain was reduced by 50\% (Cerede et al., 2005; Blumenschein et al., 2007; Friedrich et al., 2010).

TgMIC4 is distributed and approximately equal in the life stages of tachyzoites, bradyzoites, merozoites and oocysts of T. gondii. Its gene length is $1743 \mathrm{bp}$, containing 580 amino acid residues, and $\mathrm{Mr}$ is $61 \mathrm{kDa}$. TgMIC4 is composed of six apple domains, the apple domains 1 and 2, 3 and 4, and 5 and 6 are separated only by 3 amino acid residues, so they are pairing and the first and second domains referred to as MIC4A12 (residues 67-230), the third and fourth ones as MIC4-A34 (residues 231-417), while the fifth and sixth ones as MIC4A56 (residues 418-580) (Brecht et al., 2001; Brown et al., 2003; Coley et al., 2007; Dereeper et al., 2008; Gronwald et al., 2008). The MIC4-A12 domains directly interact with the two MAR domains of MIC1 (Reiss et al., 2001; Saouros et al., 2005, 2007). In mic4 ko strains, part of TgMIC1-6 complex was transferred to the micronemes, and only MIC4-A12 supplementation was sufficient to restore the excretion of TgMIC4 from the early secretory compartment and be sorted into the micronemes correctly. The functions of the MIC4-A34 domains are currently unclear. The A5 domain is a lectin with specificity for $\beta 1-3$-or $\beta 1-4$-galactosamine which is cleaved from the complex and is responsible for cell adhesion during parasite invasion (Yoshida et al., 2010; Marchant et al., 2012; Sardinha-Silva et al., 2019). TgMIC4 is initially synthesized in the form of a full-length $72-\mathrm{kDa}$ and stored in micronemes. After discharge from the micronemes, microneme protein protease (MPP) 3 first cleaves the N-terminus of TgMIC4 into a $70-\mathrm{kDa}$ species, followed by the release of 50- and $15-\mathrm{kDa}$ fragments at the C-terminal through the MPP2 hydrolysis, exposing its galectin domain and promote tight binding to host cell receptors (Brecht et al., 2001; Brossier et al., 2005; Dowse et al., 2005; Figure 1).

TgMIC6 is a $34 \mathrm{kDa}$ type I transmembrane protein that anchors the complex to the parasite membrane during the invasion. It contains three EGF-like domains (Keates et al., 2001; Meissner et al., 2002a; Koff et al., 2006), a transmembrane domain, and a carboxyl-terminal cytoplasmic domain (Reiss et al., 2001; Figure 1). The EGF domain is composed of 30-40 amino acid residues, contains six cysteine residues, which form three disulfide bonds, and is an evolutionarily conserved protein domain that widely presents in membrane-bound proteins and extracellular eukaryotic proteins, generally increases specificity through multivalent interaction and participates in many different biological functions (Davis, 1990; Li et al., 2015). A classification signal based on tyrosine residues in the C-terminal cytoplasmic domain of TgMIC6 is also critical for the correct transport of the complex to the micronemes. It is possible that the TgMIC1 galectin-like domain assists in the folding of the TgMIC6 C-terminal, so that the complex can exit from the ER and the Golgi, and then accurately transported into the microneme through the sorting signal (Reiss et al., 2001; Saouros et al., 2005). The knockout of TgMIC6 or its cytoplasmic region can cause TgMIC1 and TgMIC4 to remain in dense granules along the secretory pathway (Saouros et al., 2005). While TgMIC6 is transported into the trans-Golgi network (TGN) after synthesis, cathepsin L-like protease (CPL) is responsible for removing its first and partial second EGF-like domain (Figure 1; Reiss et al., 2001; Parussini et al., 2010). The role of this predomain removal is unclear, but it does not impact on the interaction between TgMIC6 and TgMIC1 (Parussini et al., 2010). After the complex is secreted outside the parasite, TgMIC6 is responsible for anchoring the complex on the surface, interacting with the actin-myosin system in the parasite, and gradually transfer to the back to provide power to penetrate the host. And then, rhomboid (ROM) 4, ROM5 and MPP1 hydrolyze the intramembrane region of the C-terminal transmembrane domain, so that the complex can be cleaved off the surface of T. gondii and disconnected from the host cell, resulting in an effective invasion.

After TgMIC1/4/6 undergo conformation-dependent sorting and proteolytic processing events to obtain functional integrity, the regulation of their secretion becomes a necessary condition for the invasion of $T$. gondii into host cells, and the level of calcium ions in the parasites plays a key role in this process. Under normal circumstances, TgMICs secretion occurs at extremely low levels (Carruthers et al., 1999; Carruthers and Sibley, 1999), but while the parasite contacts the host cell surface, it triggers a signal cascade, which stimulates the release of large amounts of calcium stored in the ER, mitochondria, and acidocalcisomes (Bonhomme et al., 1993; Miranda et al., 2010), thereby leading to the secretion and accumulation of numerous MICs on the parasites surface, mediating the gliding motility and invasion (Figure 2). Previous studies showed that inositol 1,4,5trisphosphate (IP3) (Fang et al., 2006; Bullen and Soldati-Favre, 2016) and cyclic ADP ribose (cADPR) can mediate the release of intracellular $\mathrm{Ca}^{2+}$. These signaling molecules require secondary messengers such as phosphatidylinositol phospholipase C (PIPLC) (Bullen and Soldati-Favre, 2016), cADPR cyclase and hydrolase to mediate $\mathrm{Ca}^{2+}$ release from the ER, however, there is no data on the existence of secondary messenger receptors (Nagamune et al., 2008; Jones et al., 2009; Singh et al., 2010). It has also been found that calcium-dependent protein kinase 1 (TgCDPK1) (Lourido et al., 2010, 2012; Lourido and Moreno, 2015; Brochet and Billker, 2016) and cyclic GMP (cGMP) activated protein kinase G (PKG) (Brown et al., 2017) which play a role in the downstream pathway of $\mathrm{Ca}^{2+}$, specifically regulating the secretion of MICs until the end of invasion, and after that within the host cell, T. gondii ER uptakes $\mathrm{Ca}^{2+}$ to store via SERCA-type $\mathrm{Ca}^{2+}$-ATPases, in order to use in the process of egress and the next invasion (Figure 2; Billker et al., 2009; Lourido and Moreno, 2015). $\mathrm{Ca}^{2+}$-mobilizing agents such as calcium ionophores, thapsigargin, ethanol have been shown to stimulate the increase of intracellular calcium levels in $T$. gondii 


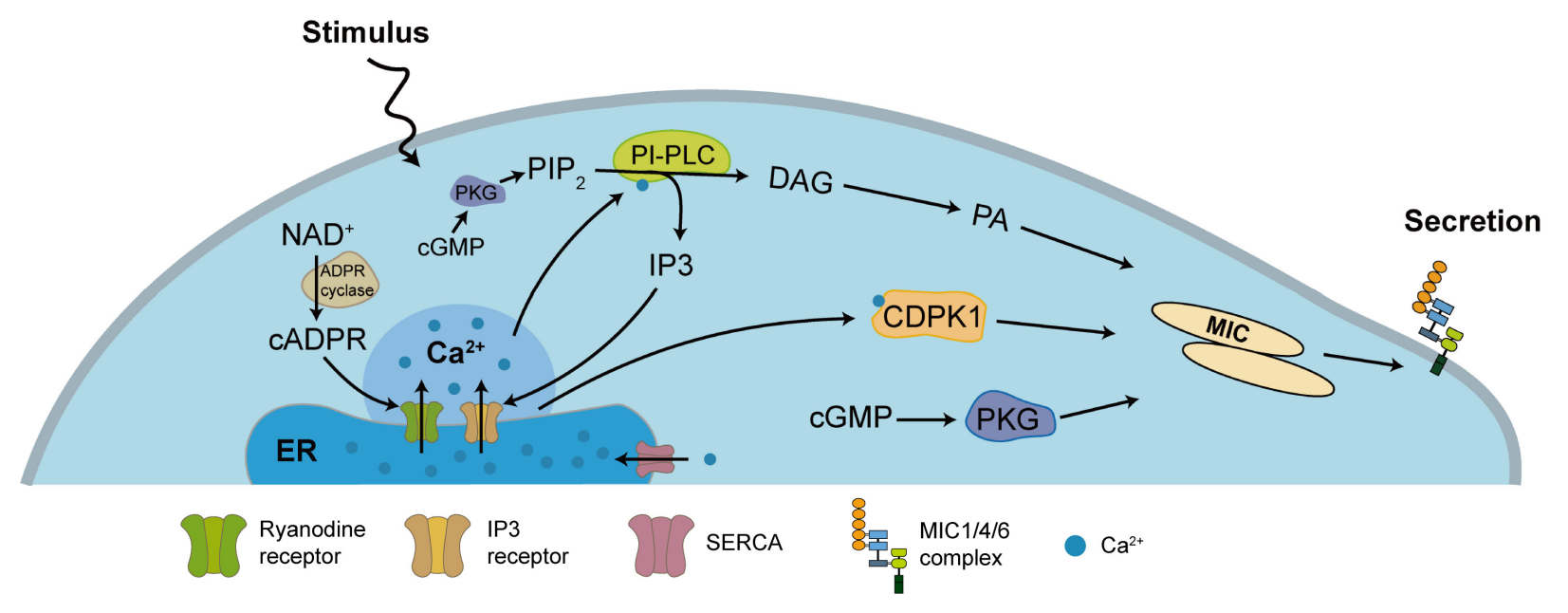

FIGURE 2 | $\mathrm{Ca}^{2+}$-dependent secretory regulation pathway of TgMIC1/4/6. Most of $\mathrm{Ca}^{2+}$ in T. gondii are stored in the ER and produce a series of signaling cascades after stimulation. PIP 2 generates IP3 and DAG through PLC, or NAD ${ }^{+}$generates cADP-ribose through ADP ribosyl cyclase, and releases Ca ${ }^{2+}$ into the cytoplasm by the action of the $\mathrm{Ca}^{2+}$ channel on the ER membrane, which further converts DAG into phosphatidic acid (PA), and also activates CDPK1 to stimulate MICs secretion. Independently, activation of cGMP can activate PKG, which is also important for controlling MICs secretion. Other studies in the malaria parasite indicate that cGMP and PKG also indirectly control the synthesis of $\mathrm{PIP}_{2}$. On the other hand, SERCA pumps Ca ${ }^{2+}$ back into the lumen of the ER to restore the level of $\mathrm{Ca}^{2+}$ in the ER and cytoplasm.

(Kawase et al., 2007). In recent years, there have also been reports that $T$. gondii can also use sex steroid hormones such as estradiol and progesterone to regulate intracellular $\mathrm{Ca}^{2+}$ signaling to promote infection and reproduction (Zhang et al., 2017, 2018). This may also be one of the reasons for the high transmission frequency and high incidence of $T$. gondii during pregnancy (Roberts et al., 2001).

\section{TgMIC1/4/6 COMPLEX IN THE INVASION OF TOXOPLASMA}

Unlike the mechanisms by which viruses and bacteria enter the cell through endocytosis or phagocytosis, T. gondii secreted a large amount of MICs during early contact of apical end with the host cell plasma membrane to establish connection with host cell receptors, and mediate gliding movement through interaction with the parasite actin-myosin system to invade host cells actively (Dobrowolski et al., 1997; Meissner et al., 2002b; Carruthers and Tomley, 2008; Soldati-Favre, 2008). It is generally believed that in the microneme protein complexes, adhesion proteins act as host cell receptor ligands, providing a "molecular bridge" for the combination of parasites and host cells, and transmembrane proteins establish a connection with the parasite actin-myosin system through their cytoplasmic tails, providing the power for penetration, and thus initiating an active invasion (Zheng et al., 2009; Figure 3). As the first such complex found in T. gondii, TgMIC1/4/6 is very typical.

Initially, Lourenço et al. (2001) first identified proteins from T. gondii with lectin activity, isolated MIC1 and MIC4 from the lactose-bound fraction ( $\mathrm{Lac}+$ ) by affinity chromatography on an immobilized lactose column and they bound to fetuin or human A erythrocyte in a way that can be inhibited by specific carbohydrate, and demonstrated that MIC1 is the lectin present in Lac+ responsible for the adsorption to immobilized lactose and for the hemagglutinating activity. But then it was found that MIC4 instead of MIC1 binds lactose. More precisely, the recognition of host cell surface carbohydrate structures in this complex mainly depends on the MAR domain of TgMIC1 and the A5 domain of TgMIC4, which specifically recognize $\alpha 2-3$ sialyllactosamine and $\beta 1$-3- or $\beta 1$-4-galactosamine, respectively (Friedrich et al., 2010; Marchant et al., 2012). Sialic acid widely exists in glycoproteins and glycolipids on the cell surface (Wang and Brand-Miller, 2003; Varki et al., 2009), plays an important role in the interaction of many viruses and bacteria with host cells, and is the vital determinant for T. gondii to recognize and invade host cells (Blumenschein et al., 2007; Takabatake et al., 2007; Persson et al., 2008; Friedrich et al., 2010; Baba et al., 2015). When using excess sialic acid or sialidase pre-incubated human fibroblasts, the tachyzoite showed an $85 \%$ reduction in invasion efficiency (Sugioka et al., 1987), with $\mathrm{N}$-acetylneuraminic acid competitive inhibition or neuraminidase treatment of host cells, invasion can be suppressed by $90 \%$ (Blumenschein et al., 2007). Therefore, the high affinity of TgMIC1 and TgMIC4 to the side chain sialic acid moiety and terminal galactose moiety of gangliosides, which widely present in the cell membrane of neurons, may be an important factor in the tropism of T. gondii to the brain in the intermediate host (Karlsson, 1998). In addition, TgMIC1 may prevent the excretion of the parasite from the intestine after being ingested by binding to sialic acid on the gut epithelial cell wall (Cowper et al., 2012). Although the presence of TgMIC4 does not improve the host cell binding efficiency of TgMIC1 (Saouros et al., 2005), the high affinity and synergistic effects of TgMIC1, TgMIC4, and other microneme adhesion proteins on the surface receptors of different cell types may better explain the wide host range of $T$. gondii. 


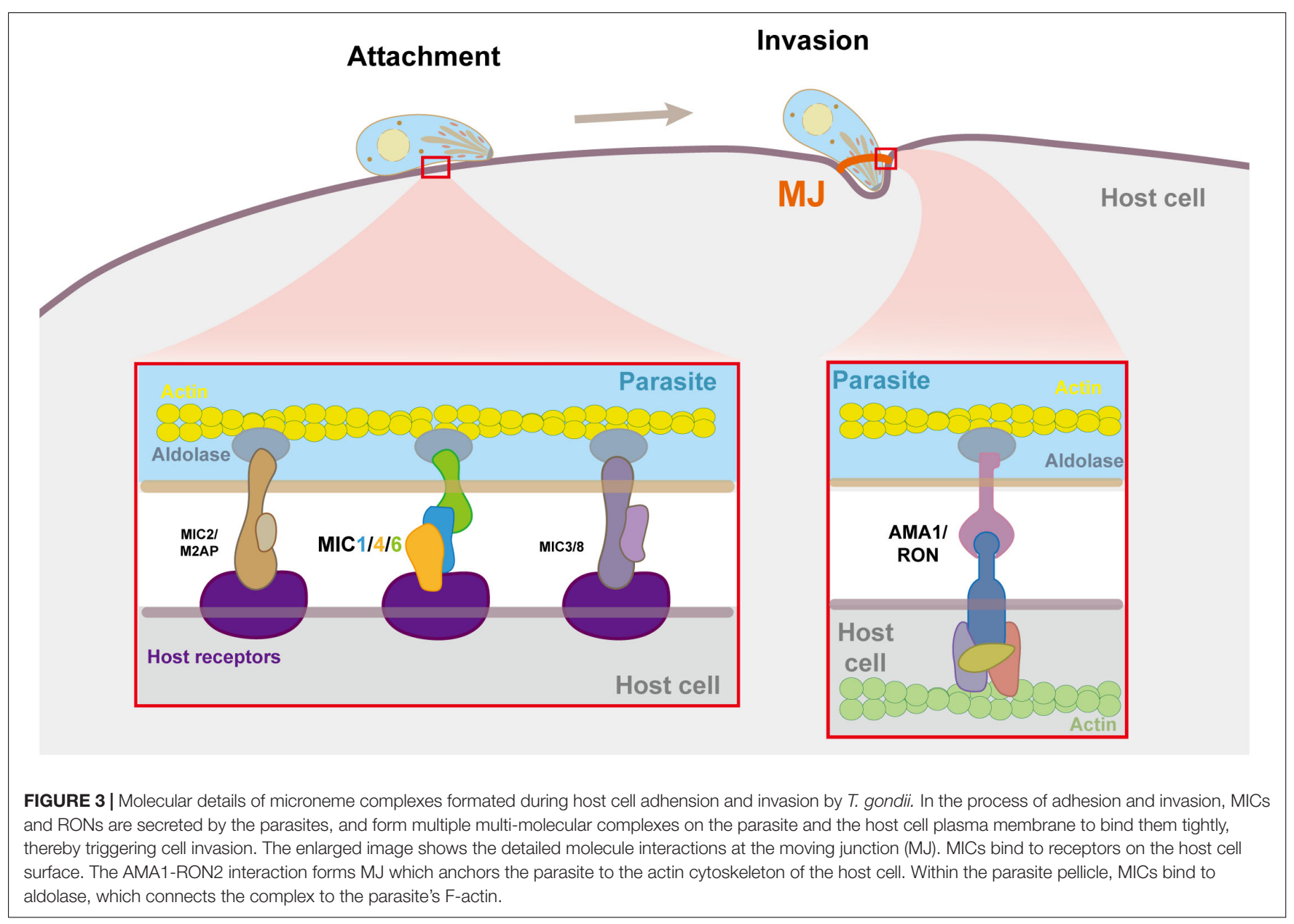

The tryptophan site in the cytoplasmic tail of TgMIC6 can interact with aldolase (Zheng et al., 2009; Boucher and Bosch, 2014), indirectly establishing a connection with the submembrane actin-myosin system in T. gondii (Figure 1), thereby driving the parasite to move in a spiral manner and actively penetrate the host cells to complete the invasion (Frenal and Soldati-Favre, 2013). Correspondingly, compared with the wild type, the invasion efficiency of mic6ko strains to host cells was reduced by about 50\% (Sawmynaden et al., 2008), which was similar to the invasion of miclko strains. However, due to the, respectively, deletion of TgMIC1 and TgMIC6 all result in the unsatisfactory targeting effect of complexes on micronemes, this invasion defect can be attributed to the absence of TgMIC1/4/6 complex without higher accuracy, but it also better illustrates the importance of this complex in invasion.

\section{TgMIC1 AND TgMIC4 ARE THE NEW IDENTIFIED SENSORS OF TLR2/4 TO INITIATE THE INNATE IMMUNITY}

As mentioned above, people used to associate TgMIC1 and TgMIC4 with the host cell adhesion more closely; however, there is currently evidence that the interaction between TgMICs with host cell receptors can lead to signal transduction events. Previous studies by Lourenço et al. (2006) demonstrated that $\mathrm{Lac}^{+}$subcomplex of T. gondii containing TgMIC1 and TgMIC4 can induce protective immunity against T. gondii via Th1type immune response, thereby reducing tissue parasitism and increasing survival rate of $T$. gondii-infected mice that were immunized with Lac+ preparation. Using TgMIC1, TgMIC4 or TgMIC6 or combinations of them as vaccines, evaluated the immune response, and determine the protection against experimental toxoplasmosis in $\mathrm{C} 57 \mathrm{BL} / 6$ mice. The results demonstrated clearly that these microneme proteins are potential vaccines against $T$. gondii because they prevented or diminished the detrimental effects of the infection (Pinzan et al., 2015). Recent studies have also demonstrated that TgMIC1, TgMIC4 and TgMIC6 are capable of inducing IFN- $\gamma$ production from $\mathrm{CD}^{+}$and $\mathrm{CD}^{+}$effector memory $\mathrm{T}$ cells in mice chronically infected with $T$. gondii, further showing the role of TgMIC1 and TgMIC4 as immunomodulators (Saraav et al., 2019). In addition, an attenuated live strain of MIC1- and MIC3 genes-deleted T. gondii (Mic1-3KO) proved to be an effective vaccine candidate in mouse and sheep models (Ismael et al., 2006; Mevelec et al., 2010), with immunogenicity, well-tolerated, and safe to the felines, although it did not abolish the oocysts shedding after natural infection with wild-type T. gondii (Le Roux et al., 2020). 
More significantly, researchers recently discovered that TgMIC1 and TgMIC4 are sensors of TLR2/4 to initiate the innate immunity (Sardinha-Silva et al., 2019). The extracellular leucine-rich repeat regions of TLR2 and TLR4 contain four and nine $\mathrm{N}$-glycans, respectively. MIC1-MAR domain and MIC4-A5 domain can directly interact with the N-glycans of the extracellular domains of TLR2 and TLR4 expressed on macrophages and dendritic cells through non-classical carbohydrate recognition, triggering MyD88-dependent NF- $\kappa$ B pathway induces innate immune cells to produce IL-12, TNF$\alpha$ and other pro-inflammatory cytokines, activate a protective immune response to produce resistance to parasites (Figure 4B). In mice infected with T. gondii, however, it is TgMIC1 instead of TgMIC4 that can cause systemic IFN- $\gamma$-induced level imbalance and pro-inflammatory cytokine storms, leading to acute death during the infection. Furthermore, they also found that in the response induced by TgMIC1/4, TLR2 heterodimerization with TLR1 or TLR6 and engagement of the co-receptors CD36 and CD14 enhanced the activation of cells, and proved that TgMIC1/4 up-regulates IL- 12 through TGF- $\beta$ activated kinase 1 (TAK1), p38 mitogen-activated protein kinase (p38), and NF- $\kappa$ B-dependent pathways (Mendonca-Natividade et al., 2019). Interestingly, in addition to inducing proinflammatory cytokine release by macrophages, MIC1 and MIC4 also trigger secretion of the antiinflammatory cytokine IL-10 through an unknown mechanism in a TLR4 internalization-dependent manner. Meanwhile, the fact that the stimulated macrophages acquired transient tolerance to LPS provides a possible mechanism for evasion of the host inflammatory response by T. gondii (Ricci-Azevedo et al., 2021).

\section{TgMIC6 HELPS THE PARASITE ESCAPE FROM THE ELIMINATION OF THE CANONICAL AUTOPHAGY PATHWAY}

Autophagy is a mechanism stimulated by innate and adaptive immune mechanisms, in which intracellular damaged or superfluous proteins and organelles are gradually surrounded by phagocytic vesicles with a double-layer membrane structure that subsequently forms autophagosomes, a structure that deliver their contents to the lysosomes for degradation (Mizushima et al., 2011). As we all know, T. gondii will form a parasitophorous vacuole $(\mathrm{PV})$ that does not fuse with host cell lysosomes after invasion. Previous studies have shown that $T$. gondii-infected macrophages can pass through the CD40 on its surface and be activated. The binding of $\mathrm{CD} 154$ on the surface of $\mathrm{CD} 4^{+} \mathrm{T}$ cells activates the upstream regulators of autophagy, such as ULK1 and Beclin1-PI3KC3, which initiates the formation of phagophore and drives the accumulation of the autophagy protein LC3 on the phagophore, thereby eliminating the T. gondii hiding in the PV (Muniz-Feliciano et al., 2013). To avoid being targeted, one of the strategies developed by T. gondii is to inhibit autophagy by activating the epidermal growth factor receptor (EGFR)/Akt signaling pathway. EGFR is expressed in a variety of cell types, including retinal pigment epithelial cells, endothelial cells, microglia and macrophages (Sobolewska et al., 2009), and is an important driver of Akt activation by T. gondii (Muniz-Feliciano et al., 2013; Purba et al., 2017). MIC3, MIC6, MIC8 have multiple domains with homology to EGF (Meissner et al., 2002a), which

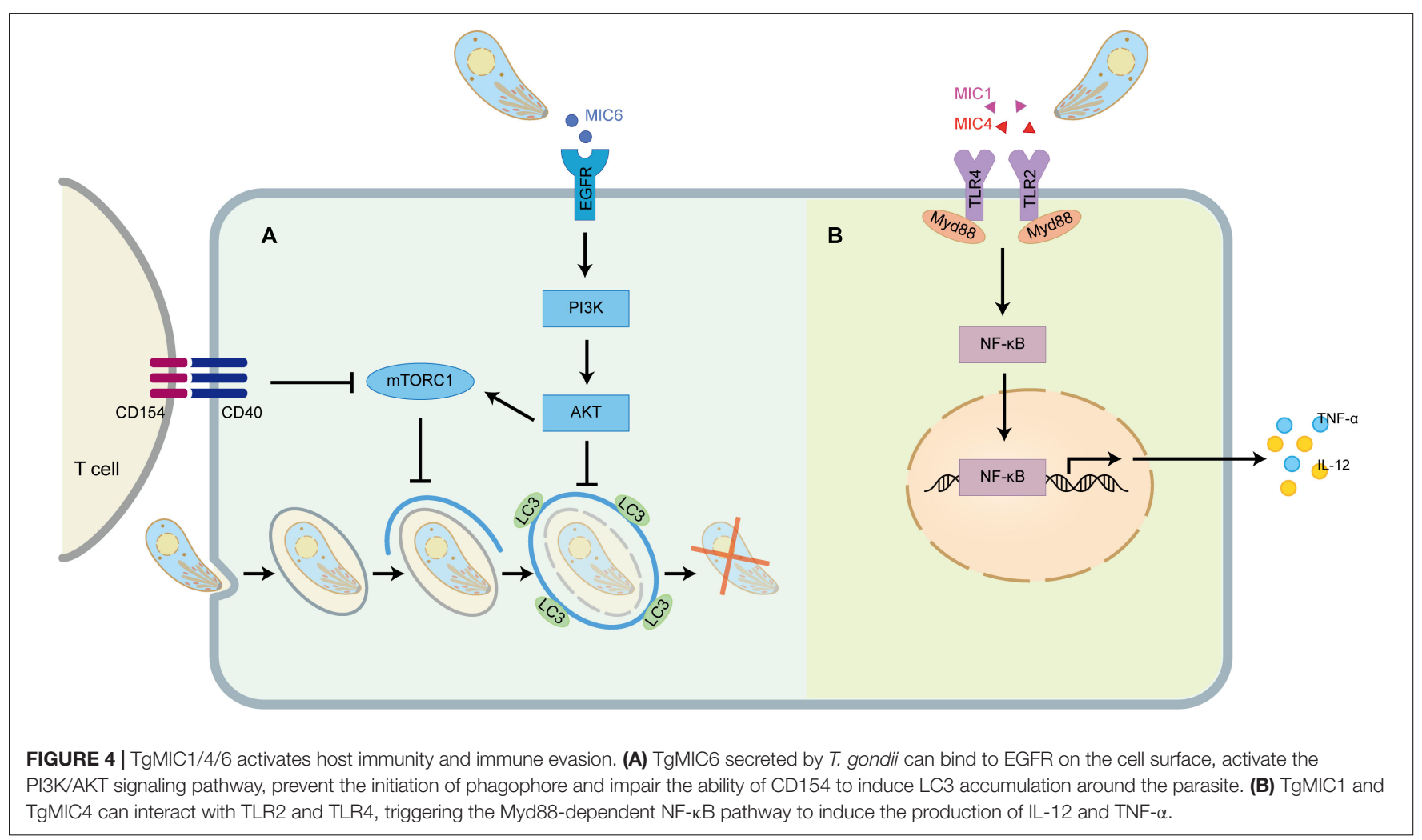


act as EGFR ligands, bind to and induce autophosphorylation of the protein at tyrosine 1,148 in host cells, and induce rapid activation of Akt through PI3K (Cabodi et al., 2004). MIC1 ko (deficient in MIC6), MIC3 ko and especially MIC1/3 ko parasites are defective in induction of EGFR-Akt activation (MunizFeliciano et al., 2013). Although MIC8 has EGF-like domains, MIC8 ko parasites show no defect in EGFR-Akt activation (Muniz-Feliciano et al., 2013). The activation of EGFR-Akt in turn activates mammalian target of rapamycin 1 (mTORC1) which downregulates autophagosome formation via CD40CD154-mediated autophagy pathway. In addition, activation of EGFR-Akt downregulates LC3 accumulation around the parasite to prevent the vacuole-lysosomal fusion, thus effectively preventing the killing of T. gondii (Figure 4A).

\section{CONCLUSION}

T. gondii is considered to be one of the most successful parasites in the world, developing a series of strategies to fight against host defense. Based on the study of the multiple functions of TgMIC1/4/6 complex, it is speculated that the complex is one of the strategies for successful parasitism. This complex can not only help T. gondii to quickly "hide" into target cells, but also help the parasite "escape" immune clearance. However, MIC1 and MIC4 proteins in the complex were found to activate innate immunity and induce protective immunity against $T$. gondii. The inconsistency of functions of the complex may be explained the delicate balance between induction and suppression of host immune response, so as to ensure the host as a safe place for T. gondii survival and allow its transmission to the end host. The domain functions of TgMIC1/4/6 and some other MICs are duplicated. For example, both TgMIC1 and TgMIC13 have MAR domains, which can recognize sialic acid oligosaccharides; TgMIC6, TgMIC3, and TgMIC8 all have multiple domains homologous to EGF, etc. Why does $T$. gondii need such a variety

\section{REFERENCES}

Anantharaman, V., Iyer, L. M., Balaji, S., and Aravind, L. (2007). Adhesion molecules and other secreted host-interaction determinants in apicomplexa: insights from comparative genomics. Int. Rev. Cytol. 262, 1-74. doi: 10.1016/ S0074-7696(07)62001-4

Baba, M., Sato, M., Kitoh, K., and Takashima, Y. (2015). The distribution pattern of alpha2,3- and alpha2,6-linked sialic acids affects host cell preference in Toxoplasma gondii. Exp. Parasitol. 155, 74-81. doi: 10.1016/j.exppara.2015.05. 005

Besteiro, S., Dubremetz, J. F., and Lebrun, M. (2011). The moving junction of apicomplexan parasites: a key structure for invasion. Cell. Microbiol. 13, 797-805. doi: 10.1111/j.1462-5822.2011.01597.x

Billker, O., Lourido, S., and Sibley, L. D. (2009). Calcium-dependent signaling and kinases in apicomplexan parasites. Cell Host Microbe 5, 612-622. doi: 10.1016/ j.chom.2009.05.017

Blumenschein, T. M. A., Friedrich, N., Childs, R. A., Saouros, S., Carpenter, E. P., Campanero-Rhodes, M. A., et al. (2007). Atomic resolution insight into host cell recognition by Toxoplasma gondii. EMBO J. 26, 2808-2820. doi: 10.1038/sj. emboj.7601704

Bonhomme, A., Pingret, L., Bonhomme, P., Michel, J., Balossier, G., Lhotel, M., et al. (1993). Subcellular calcium localization in Toxoplasma gondii by electron microscopy and by X-ray and electron energy loss spectroscopies. Microsc. Res. Tech. 25, 276-285. doi: 10.1002/jemt.1070250403 of MICs and duplicate domains? Are their functions redundant? One of our speculations is that the diversity of this molecule may be to recognize a wider range of host receptors, coordinate the immune regulation of host cells, and ensure the efficient invasion and survival of $T$. gondii against a variety of host cells. This is effectively reflected in the up-regulated expression of AMA1 and RON2 homologs in AMA1 knockout strains, which compensatively supported residual invasion (Lamarque et al., 2014). In addition, there is increasing evidence that TgMIC1, TgMIC4, and TgMIC6 are effective antigen targets and candidate vaccines, which can induce protective immunity against $T$. gondii through TH1 specific immune response. Nevertheless, there is still much work to be done on the study of MICs, and we believe that with the development of molecular biology and genetic engineering technology, more MIC complexes may be discovered, and further breakthroughs will be made in parasitehost interaction, signal recognition, structure and function.

\section{AUTHOR CONTRIBUTIONS}

LY and JZ designed the work. JZ and YW drafted the article and diagramming. YC, JS, and LY did critical revision of the article. All authors contributed to the article and approved the submitted version.

\section{FUNDING}

This work was supported in part by the National Key R\&D Program of China (2017YFD0500400 to LY), the National Natural Science Foundation of China (82072304, 81871671 and 81572022 to LY, 81802003 to YC), Outstanding Young Scholars Financial Support of Anhui Medical University (0113014104 to LY), and promotion plan of basic and clinical cooperative research in Anhui Medical University (2019 xkjT023 to LY).

Boucher, L. E., and Bosch, J. (2014). Structure of Toxoplasma gondii fructose-1,6-bisphosphate aldolase. Acta Crystallogr. F Struct. Biol. Commun. 70(Pt 9), 1186-1192. doi: 10.1107/S2053230X140 17087

Boucher, L. E., and Bosch, J. (2015). The apicomplexan glideosome and adhesins structures and function. J. Struct. Biol. 190, 93-114. doi: 10.1016/j.jsb.2015.02. 008

Brecht, S., Carruthers, V. B., Ferguson, D. J., Giddings, O. K., Wang, G., Jakle, U., et al. (2001). The toxoplasma micronemal protein MIC4 is an adhesin composed of six conserved apple domains. J. Biol. Chem. 276, 4119-4127. doi: 10.1074/jbc.M008294200

Brochet, M., and Billker, O. (2016). Calcium signalling in malaria parasites. Mol. Microbiol. 100, 397-408. doi: 10.1111/mmi.13324

Brossier, F., Jewett, T. J., Sibley, L. D., and Urban, S. (2005). A spatially localized rhomboid protease cleaves cell surface adhesins essential for invasion by Toxoplasma. Proc. Natl. Acad. Sci. U.S.A. 102, 4146-4151. doi: 10.1073/pnas. 0407918102

Brown, K. M., Long, S., and Sibley, L. D. (2017). Plasma membrane association by N-acylation governs PKG function in Toxoplasma gondii. mBio 8:e00375-17. doi: $10.1128 / \mathrm{mBio} .00375-17$

Brown, P. J., Mulvey, D., Potts, J. R., Tomley, F. M., and Campbell, I. D. (2003). Solution structure of a PAN module from the apicomplexan parasite Eimeria tenella. J. Struct. Funct. Genomics 4, 227-234. doi: 10.1023/b:jsfg.0000016118. 87333.03 
Bullen, H. E., and Soldati-Favre, D. (2016). A central role for phosphatidic acid as a lipid mediator of regulated exocytosis in apicomplexa. FEBS Lett. 590, 2469-2481. doi: 10.1002/1873-3468.12296

Cabodi, S., Moro, L., Bergatto, E., Boeri Erba, E., Di Stefano, P., Turco, E., et al. (2004). Integrin regulation of epidermal growth factor (EGF) receptor and of EGF-dependent responses. Biochem. Soc. Trans. 32(Pt 3), 438-442. doi: 10. 1042/BST0320438

Carruthers, V. B., and Boothroyd, J. C. (2007). Pulling together: an integrated model of Toxoplasma cell invasion. Curr. Opin. Microbiol. 10, $82-89$.

Carruthers, V. B., and Sibley, L. D. (1997). Sequential protein secretion from three distinct organelles of Toxoplasma gondii accompanies invasion of human fibroblasts. Eur. J. Cell Biol. 73, 114-123.

Carruthers, V. B., and Sibley, L. D. (1999). Mobilization of intracellular calcium stimulates microneme discharge in Toxoplasma gondii. Mol. Microbiol. 31, 421-428. doi: 10.1046/j.1365-2958.1999.01174.x

Carruthers, V. B., and Tomley, F. M. (2008). Microneme proteins in apicomplexans. Subcell. Biochem. 47, 33-45. doi: 10.1007/978-0-387-782 67-6_2

Carruthers, V. B., Giddings, O. K., and Sibley, L. D. (1999). Secretion of micronemal proteins is associated with toxoplasma invasion of host cells. Cell. Microbiol. 1, 225-235. doi: 10.1046/j.1462-5822.1999.00023.x

Cerede, O., Dubremetz, J. F., Soete, M., Deslee, D., Vial, H., Bout, D., et al. (2005). Synergistic role of micronemal proteins in Toxoplasma gondii virulence. J. Exp. Med. 201, 453-463. doi: 10.1084/jem.20041672

Checkley, W., White, A. C., Jaganath, D., Arrowood, M. J., Chalmers, R. M., Chen, X. M., et al. (2015). A review of the global burden, novel diagnostics, therapeutics, and vaccine targets for Cryptosporidium. Lancet Infect. Dis. 15, 85-94. doi: 10.1016/S1473-3099(14)70772-8

Coley, A. M., Gupta, A., Murphy, V. J., Bai, T., Kim, H., Foley, M., et al. (2007). Structure of the malaria antigen AMA1 in complex with a growth-inhibitory antibody. PLoS Pathog. 3:1308-1319. doi: 10.1371/journal.ppat.0030138

Cowper, B., Matthews, S., and Tomley, F. (2012). The molecular basis for the distinct host and tissue tropisms of coccidian parasites. Mol. Biochem. Parasitol. 186, 1-10. doi: 10.1016/j.molbiopara.2012.08.007

Davis, C. G. (1990). The many faces of epidermal growth factor repeats. New Biol. 2, 410-419.

Dereeper, A., Guignon, V., Blanc, G., Audic, S., Buffet, S., Chevenet, F., et al. (2008). Phylogeny.fr: robust phylogenetic analysis for the non-specialist. Nucleic Acids Res. 36, W465-W469. doi: 10.1093/nar/gkn180

Di Cristina, M., Spaccapelo, R., Soldati, D., Bistoni, F., and Crisanti, A. (2000). Two conserved amino acid motifs mediate protein targeting to the micronemes of the apicomplexan parasite Toxoplasma gondii. Mol. Cell. Biol. 20, 7332-7341. doi: $10.1128 / \mathrm{mcb} \cdot 20.19 .7332-7341.2000$

Dobrowolski, J. M., Carruthers, V. B., and Sibley, L. D. (1997). Participation of myosin in gliding motility and host cell invasion by Toxoplasma gondii. Mol. Microbiol. 26, 163-173. doi: 10.1046/j.1365-2958.1997.5671913.x

Dowse, T. J., Pascall, J. C., Brown, K. D., and Soldati, D. (2005). Apicomplexan rhomboids have a potential role in microneme protein cleavage during host cell invasion. Int. J. Parasitol. 35, 747-756. doi: 10.1016/j.ijpara.2005.04.001

Fang, J., Marchesini, N., and Moreno, S. N. (2006). A Toxoplasma gondii phosphoinositide phospholipase C (TgPI-PLC) with high affinity for phosphatidylinositol. Biochem. J. 394(Pt 2), 417-425. doi: 10.1042/BJ20051393

Fourmaux, M. N., Achbarou, A., Mercereau-Puijalon, O., Biderre, C., Briche, I., Loyens, A., et al. (1996). The MIC1 microneme protein of Toxoplasma gondii contains a duplicated receptor-like domain and binds to host cell surface. Mol. Biochem. Parasitol. 83, 201-210. doi: 10.1016/s0166-6851(96)02773-9

Frenal, K., and Soldati-Favre, D. (2013). [The glideosome, a unique machinery that assists the Apicomplexa in gliding into host cells]. Med. Sci. 29, 515-522. doi: $10.1051 / \mathrm{medsci} / 2013295015$

Friedrich, N., Santos, J. M., Liu, Y., Palma, A. S., Leon, E., Saouros, S., et al. (2010). Members of a novel protein family containing microneme adhesive repeat domains act as sialic acid-binding lectins during host cell invasion by apicomplexan parasites. J. Biol. Chem. 285, 2064-2076. doi: 10.1074/jbc.M109. 060988

Garnett, J. A., Liu, Y., Leon, E., Allman, S. A., Friedrich, N., Saouros, S., et al. (2009). Detailed insights from microarray and crystallographic studies into carbohydrate recognition by microneme protein 1 (MIC1) of Toxoplasma gondii. Protein Sci. 18, 1935-1947. doi: 10.1002/pro.204
Gay, N. J., Symmons, M. F., Gangloff, M., and Bryant, C. E. (2014). Assembly and localization of Toll-like receptor signalling complexes. Nat. Rev. Immunol. 14, 546-558. doi: 10.1038/nri3713

Gronwald, W., Bomke, J., Maurer, T., Domogalla, B., Huber, F., Schumann, F., et al. (2008). Structure of the leech protein saratin and characterization of its binding to collagen. J. Mol. Biol. 381, 913-927. doi: 10.1016/j.jmb.2008.06.034

Huynh, M. H., and Carruthers, V. B. (2006). Toxoplasma MIC2 is a major determinant of invasion and virulence. PLoS Pathog. 2:e84. doi: 10.1371/journal. ppat. 0020084

Ismael, A. B., Dimier-Poisson, I., Lebrun, M., Dubremetz, J. F., Bout, D., and Mevelec, M. N. (2006). Mic1-3 knockout of Toxoplasma gondii is a successful vaccine against chronic and congenital toxoplasmosis in mice. J. Infect. Dis. 194, 1176-1183. doi: 10.1086/507706

Jones, M. L., Cottingham, C., and Rayner, J. C. (2009). Effects of calcium signaling on Plasmodium falciparum erythrocyte invasion and post-translational modification of gliding-associated protein 45 (PfGAP45). Mol. Biochem. Parasitol. 168, 55-62. doi: 10.1016/j.molbiopara.2009.06.007

Karlsson, K. A. (1998). On the character and functions of sphingolipids. Acta Biochim. Pol. 45, 429-438.

Kawase, O., Nishikawa, Y., Bannai, H., Zhang, H., Zhang, G., Jin, S., et al. (2007). Proteomic analysis of calcium-dependent secretion in Toxoplasma gondii. Proteomics 7, 3718-3725. doi: 10.1002/pmic.200700362

Keates, S., Sougioultzis, S., Keates, A. C., Zhao, D., Peek, R. M. Jr., Shaw, L. M., et al. (2001). cag+ Helicobacter pylori induce transactivation of the epidermal growth factor receptor in AGS gastric epithelial cells. J. Biol. Chem. 276, 48127-48134. doi: 10.1074/jbc.M107630200

Koff, J. L., Shao, M. X., Kim, S., Ueki, I. F., and Nadel, J. A. (2006). Pseudomonas lipopolysaccharide accelerates wound repair via activation of a novel epithelial cell signaling cascade. J. Immunol. 177, 8693-8700. doi: 10.4049/jimmunol.177. 12.8693

Lamarque, M. H., Roques, M., Kong-Hap, M., Tonkin, M. L., Rugarabamu, G., Marq, J. B., et al. (2014). Plasticity and redundancy among AMA-RON pairs ensure host cell entry of Toxoplasma parasites. Nat. Commun. 5:4098. doi: 10.1038/ncomms5098

Lamarque, M., Besteiro, S., Papoin, J., Roques, M., Vulliez-Le Normand, B., Morlon-Guyot, J., et al. (2011). The RON2-AMA1 interaction is a critical step in moving junction-dependent invasion by Apicomplexan parasites. PLoS Pathog. 7:e1001276. doi: 10.1371/journal.ppat.1001276

Le Roux, D., Djokic, V., Morisse, S., Chauvin, C., Dore, V., Lagree, A. C., et al. (2020). Evaluation of immunogenicity and protection of the Mic1-3 knockout Toxoplasma gondii live attenuated strain in the feline host. Vaccine 38, 14571466. doi: 10.1016/j.vaccine.2019.11.076

Li, W., Liu, J., Wang, J., Fu, Y., Nan, H., and Liu, Q. (2015). Identification and characterization of a microneme protein (NcMIC6) in Neospora caninum. Parasitol. Res. 114, 2893-2902. doi: 10.1007/s00436-015-4490-3

Lourenço, E. V., Bernardes, E. S., Silva, N. M., Mineo, J. R., Panunto-Castelo, A., and Roque-Barreira, M. C. (2006). Immunization with MIC1 and MIC4 induces protective immunity against Toxoplasma gondii. Microbes Infect. 8, 1244-1251. doi: 10.1016/j.micinf.2005.11.013

Lourenço, E. V., Pereira, S. R., Faca, V. M., Coelho-Castelo, A. A., Mineo, J. R., Roque-Barreira, M. C., et al. (2001). Toxoplasma gondii micronemal protein MIC1 is a lactose-binding lectin. Glycobiology 11, 541-547. doi: 10.1093/glycob/ 11.7.541

Lourido, S., and Moreno, S. N. (2015). The calcium signaling toolkit of the Apicomplexan parasites Toxoplasma gondii and Plasmodium spp. Cell Calcium 57, 186-193. doi: 10.1016/j.ceca.2014.12.010

Lourido, S., Shuman, J., Zhang, C., Shokat, K. M., Hui, R., and Sibley, L. D. (2010). Calcium-dependent protein kinase 1 is an essential regulator of exocytosis in Toxoplasma. Nature 465, 359-362. doi: 10.1038/nature09022

Lourido, S., Tang, K., and Sibley, L. D. (2012). Distinct signalling pathways control Toxoplasma egress and host-cell invasion. EMBO J. 31, 4524-4534. doi: 10.1038/ emboj.2012.299

Marchant, J., Cowper, B., Liu, Y., Lai, L., Pinzan, C., Marq, J. B., et al. (2012). Galactose recognition by the Apicomplexan parasite Toxoplasma gondii. J. Biol. Chem. 287, 16720-16733. doi: 10.1074/jbc.M111.325928

Meissner, M., Reiss, M., Viebig, N., Carruthers, V. B., Toursel, C., Tomavo, S., et al. (2002a). A family of transmembrane microneme proteins of Toxoplasma gondii contain EGF-like domains and function as escorters. J. Cell Sci. 115(Pt 3), 563-574. 
Meissner, M., Schluter, D., and Soldati, D. (2002b). Role of Toxoplasma gondii myosin A in powering parasite gliding and host cell invasion. Science 298, 837-840. doi: 10.1126/science. 1074553

Mendonca-Natividade, F. C., Lopes, C. D., Ricci-Azevedo, R., Sardinha-Silva, A., Pinzan, C. F., Alegre-Maller, A. C. P., et al. (2019). Receptor heterodimerization and co-receptor engagement in TLR2 activation induced by MIC1 and MIC4 from Toxoplasma gondii. Int. J. Mol. Sci. 20:5001. doi: 10.3390/ijms20205001

Mevelec, M. N., Ducournau, C., Bassuny Ismael, A., Olivier, M., Seche, E., Lebrun, M., et al. (2010). Mic1-3 Knockout Toxoplasma gondii is a good candidate for a vaccine against $T$. gondii-induced abortion in sheep. Vet. Res. 41:49. doi: $10.1051 /$ vetres/2010021

Miranda, K., Pace, D. A., Cintron, R., Rodrigues, J. C., Fang, J., Smith, A., et al. (2010). Characterization of a novel organelle in Toxoplasma gondii with similar composition and function to the plant vacuole. Mol. Microbiol. 76, 1358-1375. doi: 10.1111/j.1365-2958.2010.07165.x

Mizushima, N., Yoshimori, T., and Ohsumi, Y. (2011). The role of Atg proteins in autophagosome formation. Annu. Rev. Cell Dev. Biol. 27, 107-132. doi: 10.1146/annurev-cellbio-092910-154005

Muniz-Feliciano, L., Van Grol, J., Portillo, J. A., Liew, L., Liu, B., Carlin, C. R., et al. (2013). Toxoplasma gondii-induced activation of EGFR prevents autophagy protein-mediated killing of the parasite. PLoS Pathog. 9:e1003809. doi: 10.1371/ journal.ppat.1003809

Nagamune, K., Hicks, L. M., Fux, B., Brossier, F., Chini, E. N., and Sibley, L. D. (2008). Abscisic acid controls calcium-dependent egress and development in Toxoplasma gondii. Nature 451, 207-210. doi: 10.1038/nature06478

Paing, M. M., and Tolia, N. H. (2014). Multimeric assembly of host-pathogen adhesion complexes involved in Apicomplexan invasion. PLoS Pathog. 10:e1004120. doi: 10.1371/journal.ppat.1004120

Parussini, F., Coppens, I., Shah, P. P., Diamond, S. L., and Carruthers, V. B. (2010). Cathepsin L occupies a vacuolar compartment and is a protein maturase within the endo/exocytic system of Toxoplasma gondii. Mol. Microbiol. 76, 1340-1357. doi: 10.1111/j.1365-2958.2010.07181.x

Persson, K. E., McCallum, F. J., Reiling, L., Lister, N. A., Stubbs, J., Cowman, A. F., et al. (2008). Variation in use of erythrocyte invasion pathways by Plasmodium falciparum mediates evasion of human inhibitory antibodies. J. Clin. Invest. 118, 342-351. doi: 10.1172/JCI32138

Pinzan, C. F., Sardinha-Silva, A., Almeida, F., Lai, L., Lopes, C. D., Lourenco, E. V., et al. (2015). Vaccination with recombinant microneme proteins confers protection against experimental toxoplasmosis in mice. PLoS One 10:e143087. doi: 10.1371/journal.pone.0143087

Purba, E. R., Saita, E. I., and Maruyama, I. N. (2017). Activation of the EGF receptor by ligand binding and oncogenic mutations: the "rotation model". Cells 6:13. doi: $10.3390 /$ cells6020013

Reiss, M., Viebig, N., Brecht, S., Fourmaux, M. N., Soete, M., Di Cristina, M., et al. (2001). Identification and characterization of an escorter for two secretory adhesins in Toxoplasma gondii. J. Cell Biol. 152, 563-578. doi: 10.1083/jcb.152. 3.563

Ricci-Azevedo, R., Mendonca-Natividade, F. C., Santana, A. C., Diniz, J. A., and Roque-Barreira, M. C. (2021). Microneme proteins 1 and 4 from Toxoplasma gondii induce IL-10 production by macrophages through TLR4 endocytosis. Front. Immunol. 12:655371. doi: 10.3389/fimmu.2021.655371

Roberts, C. W., Walker, W., and Alexander, J. (2001). Sex-associated hormones and immunity to protozoan parasites. Clin. Microbiol. Rev. 14, 476-488. doi: 10.1128/CMR.14.3.476-488.2001

Santos, J. M., and Soldati-Favre, D. (2011). Invasion factors are coupled to key signalling events leading to the establishment of infection in apicomplexan parasites. Cell. Microbiol. 13, 787-796. doi: 10.1111/j.1462-5822.2011.01585.x

Saouros, S., Blumenschein, T. M., Sawmynaden, K., Marchant, J., Koutroukides, T., Liu, B., et al. (2007). High-level bacterial expression and purification of apicomplexan micronemal proteins for structural studies. Protein Pept. Lett. 14, 411-415. doi: 10.2174/092986607780782876

Saouros, S., Edwards-Jones, B., Reiss, M., Sawmynaden, K., Cota, E., Simpson, P., et al. (2005). A novel galectin-like domain from Toxoplasma gondii micronemal protein 1 assists the folding, assembly, and transport of a cell adhesion complex. J. Biol. Chem. 280, 38583-38591. doi: 10.1074/jbc.C500365200

Saraav, I., Wang, Q., Brown, K. M., and Sibley, L. D. (2019). Secretory microneme proteins induce $\mathrm{T}$-cell recall responses in mice chronically infected with Toxoplasma gondii. mSphere 4:e0711-18. doi: 10.1128/mSphere.00711-18
Sardinha-Silva, A., Mendonca-Natividade, F. C., Pinzan, C. F., Lopes, C. D., Costa, D. L., Jacot, D., et al. (2019). The lectin-specific activity of Toxoplasma gondii microneme proteins 1 and 4 binds Toll-like receptor 2 and $4 \mathrm{~N}$-glycans to regulate innate immune priming. PLoS Pathog. 15:e1007871. doi: 10.1371/ journal.ppat.1007871

Sawmynaden, K., Saouros, S., Friedrich, N., Marchant, J., Simpson, P., Bleijlevens, B., et al. (2008). Structural insights into microneme protein assembly reveal a new mode of EGF domain recognition. EMBO Rep. 9, 1149-1155. doi: 10.1038/ embor.2008.179

Sheiner, L., Santos, J. M., Klages, N., Parussini, F., Jemmely, N., Friedrich, N., et al. (2010). Toxoplasma gondii transmembrane microneme proteins and their modular design. Mol. Microbiol. 77, 912-929. doi: 10.1111/j.1365-2958.2010. 07255.x

Sibley, L. D. (2011). Invasion and intracellular survival by protozoan parasites. Immunol. Rev. 240, 72-91. doi: 10.1111/j.1600-065X.2010.00990.x

Singh, S., Alam, M. M., Pal-Bhowmick, I., Brzostowski, J. A., and Chitnis, C. E. (2010). Distinct external signals trigger sequential release of apical organelles during erythrocyte invasion by malaria parasites. PLoS Pathog. 6:e1000746. doi: 10.1371/journal.ppat.1000746

Sobolewska, A., Gajewska, M., Zarzynska, J., Gajkowska, B., and Motyl, T. (2009). IGF-I, EGF, and sex steroids regulate autophagy in bovine mammary epithelial cells via the mTOR pathway. Eur. J. Cell Biol. 88, 117-130. doi: 10.1016/j.ejcb. 2008.09.004

Soldati-Favre, D. (2008). Molecular dissection of host cell invasion by the apicomplexans: the glideosome. Parasite 15, 197-205. doi: 10.1051/parasite/ 2008153197

Sugioka, Y., Suzuki, M., Sugioka, K., and Nakano, M. (1987). A ferriprotoporphyrin IX-chloroquine complex promotes membrane phospholipid peroxidation. A possible mechanism for antimalarial action. FEBS Lett. 223, 251-254. doi: 10.1016/0014-5793(87)80299-5

Takabatake, N., Okamura, M., Yokoyama, N., Ikehara, Y., Akimitsu, N., Arimitsu, N., et al. (2007). Glycophorin A-knockout mice, which lost sialoglycoproteins from the red blood cell membrane, are resistant to lethal infection of Babesia rodhaini. Vet. Parasitol. 148, 93-101. doi: 10.1016/j.vetpar.2007.06.011

Tomley, F. M., and Soldati, D. S. (2001). Mix and match modules: structure and function of microneme proteins in apicomplexan parasites. Trends Parasitol. 17, 81-88. doi: 10.1016/s1471-4922(00)01761-x

Varki, A., Cummings, R. D., Esko, J. D., Freeze, H. H., Stanley, P., Marth, J. D., et al. (2009). Symbol nomenclature for glycan representation. Proteomics 9, 5398-5399. doi: 10.1002/pmic.200900708

Wang, B., and Brand-Miller, J. (2003). The role and potential of sialic acid in human nutrition. Eur. J. Clin. Nutr. 57, 1351-1369. doi: 10.1038/sj.ejcn.1601704

Yoshida, H., Teraoka, M., Nishi, N., Nakakita, S., Nakamura, T., Hirashima, M., et al. (2010). X-ray structures of human galectin-9 C-terminal domain in complexes with a biantennary oligosaccharide and sialyllactose. J. Biol. Chem. 285, 36969-36976. doi: 10.1074/jbc.M110.163402

Zhang, X., Liu, J., Li, M., Fu, Y., Zhang, T., Han, Q., et al. (2017). Role of an estradiol regulatory factor-hydroxysteroid dehydrogenase (HSD) in Toxoplasma gondii infection and pathogenicity. J. Steroid Biochem. Mol. Biol. 174, 176-182. doi: 10.1016/j.jsbmb.2017.09.001

Zhang, X., Zhang, H., Fu, Y., Liu, J., and Liu, Q. (2018). Effects of estradiol and progesterone-induced intracellular calcium fluxes on Toxoplasma gondii gliding, microneme secretion, and egress. Front. Microbiol. 9:1266. doi: 10.3389/ fmicb.2018.01266

Zheng, B., He, A., Gan, M., Li, Z., He, H., and Zhan, X. (2009). MIC6 associates with aldolase in host cell invasion by Toxoplasma gondii. Parasitol. Res. 105, 441-445. doi: 10.1007/s00436-009-1401-5

Conflict of Interest: The authors declare that the research was conducted in the absence of any commercial or financial relationships that could be construed as a potential conflict of interest.

Copyright (c) 2021 Zhu, Wang, Cao, Shen and Yu. This is an open-access article distributed under the terms of the Creative Commons Attribution License (CC BY). The use, distribution or reproduction in other forums is permitted, provided the original author(s) and the copyright owner(s) are credited and that the original publication in this journal is cited, in accordance with accepted academic practice. No use, distribution or reproduction is permitted which does not comply with these terms. 